\title{
Compact Urban Constructions and Disease Outbreaks
}

\author{
Abbas Ziafati Bafarasat* \\ Department of Urban and Regional Planning, Yazd University, Iran
}

*Corresponding author: Abbas Ziafati Bafarasat, Urban and Regional Planning,

Yazd University, Iran. Email: abbas.ziafatibafarasat@yazd.ac.ir

Received Date: March 02, 2020

Published Date: March 12, 2020

\section{Introduction}


Figure 1: A) Wuhan City of China (top) and B) Qom City of Iran - compact cities which became Coronavirus epicenters (Source: Google Maps).

In 2017, I wrote a paper questioning the unproblematic promotion of compact urban constructions in developing countries not only on social grounds but also in terms of its linchpin of car travel reduction: "If a 5\% reduction is assumed in car travel distance in the sample districts in the context of density, and, under the optimistic scenario, that the time-distance ratio is 1 in high density areas, this finding feeds into the conclusion that high density might have had no positive effect on, or even increased to a limited degree, the overall time of car travel" [1]. 
The swift spread of Coronavirus in Wuhan (Figure 1), which is the most densely populated city in central China, has now led physicians to argue that such densely packed hubs are particularly vulnerable and may need a redesign [2]. This argument is, for example, evidenced by research from the University of Geneva: "The world's densest cities are in Asia... Population density affects diseases, particularly those transmitted via respiratory and faecaloral routes. Because of high-population density, an increased amount of shared airspace increases exposure to influenza, measles, and Mycobacterium tuberculosis" [3].

Qom City (Figure 1), in which Iran's Coronavirus outbreak began, has a population density of $7257 / \mathrm{km} 2$. This nearly matches Singapore's which is also a main outbreak center outside China. In a similar vein, the epicenter of Sars, or severe acute respiratory syndrome which killed more than 770 people between 2002 and 2003, was a housing estate in Hong Kong, among the most densely populated cities in the world [4]. Meanwhile, Daegu City, which is South Korea's Coronavirus hub, has been pursuing a compact model of urban development [5], and ideas such as building "20-minute cities", where one can get to their job, the doctor or their friends all within 20 minutes, to a significant extant rely on densification of construction [6].

Whilst the now 'pandemic' seems to affect many less compact cities partly due to an initial lack of political desire to quarantine outbreak centers, the question of 'appropriate' compactness and 'sustainable' population densities [7] should increasingly consider the following criteria:

Intra and inter institutional capacities of departmental sectors (such as health, housing and transportation) and urban governance

Where these capacities are low, compact urban development creates more problems than it solves, in particular, in times of crisis. In other words, only well-equipped and 'thick' institutional contexts [8] can make significant service adjustments and resource pooling without awaiting higher level command or engaging in political arguments.

\section{Accountable specific powers}

This makes sure that multi-level governance, local autonomy and populistic considerations do not paralyze those crisis responses that should be provided top-down, and, on the other hand, any such decisions and application of specific regulations are held to account post crisis.

\section{Relationships of trust}

Without this, government's attempt to manage citizens' behavior during outbreaks in a dense setting will be less effective, for example, in terms of preventing panic buying; and

\section{Land price influence}

Where strict limitations on urban expansion compromise housing affordability, more people are likely to end up home sharing and slum dwelling with higher exposure to outbreaks. Interestingly, many cities in Asia pursuing compact development, such as Qom in Iran, are surrounded by vast desert land with no limitation for future expansion.

\section{Acknowledgement}

None.

\section{Conflict of Interest}

No conflict of interest.

\section{References}

1. Ziafati Bafarasat A (2017) Invisible travels in the compact city: Is density the way forward? Journal of Urban Planning and Development 143(3): 1-10.

2. Bendix A (2020) The Chinese city of Wuhan was a breeding ground for an outbreak, experts say. The Coronavirus has infected more than 870 people. Business Insider, 24 January. https://www.businessinsider. com/wuhan-china-breeding-ground-for-coronavirus-outbreak-2020-1

3. Alirol E, Getaz L, Stoll B, Chappuis F, Loutan L (2011) Urbanisation and infectious diseases in a globalised world. Lancet Infect Dis 11(2): 131141.

4. The Straits Times (2020) Coronavirus outbreak shows vulnerability of densely packed cities, highlights need for redesign, say experts. The Straits Times, 17 February. https://www.straitstimes.com/asia/ se-asia/amid-coronavirus-outbreak-experts-say-densely-packed-citiesbear-the-brunt-and-need.

5. Joo YM, Seo B (2018) Dual policy to fight urban shrinkage: Daegu, South Korea. Cities 73: 128-137.

6. Stanley, Janet, Stanley, John (2014) Achieving the 20minute city for Melbourne: Turning our city upside down. Paper prepared for Bus Association Victoria. Australia.

7. United Nations (2017) New Urban Agenda. New York, USA.

8. Paraskevopoulos CJ (2002) New institutionalism and EU regional policy: multi-level governance by" thin" or " thick" institutions?. Current Politics and Economics of Europe 11(2): 159-179. 